\title{
Modelagem Matemática na Educação Matemática e Formação Continuada de Professores: caminhos para o desenvolvimento profissional
}

\author{
Mathematical Modeling in Mathematics Educationand Continuing Teacher \\ Education: paths to professional development
}

\author{
Rosi Kelly Regina Marmitt \\ Danusa de Lara Bonotto
}

\begin{abstract}
Resumo: Este artigo tem como objetivo conhecer as pesquisas realizadas sobre Modelagem Matemática e Formação Continuada e compreender, a partir delas, o desenvolvimento profissional (DP) dos professores participantes. Para tal, utilizamos como abordagem metodológica a pesquisa qualitativa, do tipo bibliográfica, com base na busca de dados na Biblioteca Digital Brasileira de Teses e Dissertações. Encontramos quatorze pesquisas, compreendidas entre 2010 e 2019 utilizando o campo busca avançada e a opção título, dentre as quais selecionamos onze para análise. Os procedimentos de análise estão pautados na análise temática de conteúdo. A partir da
\end{abstract} unidade de análise desenvolvimento profissional apresentamos duas categorias nas quais discutimos que: 1) as pesquisas tratam da formação continuada com modelagem na perspectiva do DP dos professores e os espaços/tempo constituídos para as formações favorecem o DP e 2) a transição da formação continuada para a sala de aula é um movimento de DP situado no fazer docente.

Palavras-chave: Práticas pedagógicas. Formação de Professores. Ensino de Matemática.

Abstract: This paper aims to recognize the research carried out on the theme Mathematical Modeling and Continuing Education and to understand from them the professional development (DP) of the participating teachers. For this, we used as a methodological approach qualitative research, of bibliographic type, based on the search for data in the Brazilian Digital Library of Theses and Dissertations. We found

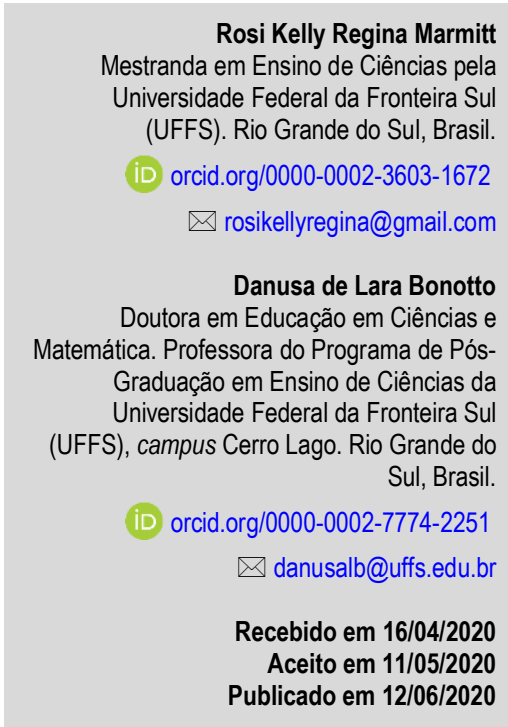

Rosi Kelly Regina Marmitt Mestranda em Ensino de Ciências pela niversidade Federal da Fronteira Sul (UFFS). Rio Grande do Sul, Brasil. Danusa de Lara Bonotto Doutora em Educaça em Cièncias e Graduação em Ensino de Ciências da Universidade Federal da Fronteira Sul Sul, Brasil. iD orcid.org/0000-0002-7774-2251

$\triangle$ danusalb@uffs.edu.br

Recebido em 16/04/2020

Publicado em 12/06/2020 fourteen surveys, between 2010 and 2019 using the advanced search field and the title option, among which we selected eleven for analysis. The analysis procedures are based on thematic content analysis. From the unit of analysis professional development we present two categories in which we discuss that: 1) the research deals with continuing education with modeling from the perspective of the teachers DP and the spaces/time constituted for the training favor the DP and 2) the transition from continuing education to the classroom is a DP movement situated in the teaching profession.

Keywords: Pedagogical practices. Teacher Training. Mathematics teaching. 


\section{Introdução}

Os fundamentos da Modelagem Matemática¹, na perspectiva da Educação Matemática, são discutidos como possibilidade para o ensino e aprendizagem de Matemática há mais de quatro décadas. Esse movimento foi fortalecido com a criação no ano de 2001, pela Sociedade Brasileira de Educação Matemática (SBEM), do Grupo de Trabalho de Modelagem Matemática - GT10, a fim de favorecer o debate e a colaboração dos pesquisadores brasileiros que realizam investigações sobre essa temática nos diferentes níveis de ensino.

As orientações das diretrizes curriculares nacionais para os cursos de Matemática bacharelado e licenciatura -, aprovadas em 2001 pelo Conselho Nacional de Educação já sinalizavam para a inserção, na matriz curricular desses cursos, de disciplinas optativas ou obrigatórias apresentadas como Tendências em Educação Matemática, dentre elas, a Modelagem Matemática (MM).

Já em 2015, a Resolução n. 2, de 1 de julho de 2015, a qual define as Diretrizes Curriculares Nacionais para a formação inicial em nível superior — cursos de licenciatura, cursos de formação pedagógica para graduados e cursos de segunda licenciatura - e para a formação continuada, orienta que a formação do professor deve estar pautada no reconhecimento da especificidade do trabalho docente, de modo que o egresso tenha o seu trabalho fundamentado em princípios de interdisciplinaridade, contextualização, pertinência e relevância social dando significado e importância aos conhecimentos e vivência da realidade social e cultural. Nesse sentido, vê-se nos pressupostos da MM na Educação Matemática uma possibilidade de articular esses princípios apresentados no documento.

A Base Nacional Comum Curricular (BNCC) proposta pelo Ministério da Educação, a qual serve de referência para a elaboração dos currículos da Educação Básica - Ensino Fundamental, de modo específico - , aponta que o trabalho com projetos de Modelagem, considerado como um processo matemático no documento, consiste numa forma de organizar a "aprendizagem matemática com base na análise de situações da vida cotidiana, de outras áreas do conhecimento e da própria matemática" (BRASIL, 2017).

Desse modo, observamos que os pressupostos da Modelagem Matemática na perspectiva da Educação Matemática têm sido sugeridos nas reformulações curriculares e podem orientar a

\footnotetext{
${ }^{1}$ A fim de evitar repetições utilizamos por vezes a palavra modelagem ou simplesmente MM para denotar a expressão Modelagem Matemática.
} 
construção de propostas pedagógicas impulsionando discussões no âmbito da formação inicial e continuada de professores.

Neste estudo, dedicamos atenção ao entrelaçamento dos fundamentos da MM com a formação continuada de professores, objetivando o reconhecimento das pesquisas realizadas no período de 2010 a 2019, bem como se as formações realizadas favorecem o desenvolvimento profissional (DP) dos professores. Para tal, organizamos este texto, apresentando inicialmente as diferentes perspectivas acerca da MM na Educação Matemática, bem como o entendimento de formação continuada na perspectiva de desenvolvimento profissional do professor. Na sequência, textualizamos os procedimentos metodológicos utilizados e apresentamos os resultados, as discussões e considerações sobre o estudo realizado.

\section{0 entendimento de Modelagem Matemática na Educação Matemática e a formação continuada de professores}

A definição de Modelo e Modelagem Matemática depende dos pressupostos teóricos assumidos, considerando que a definição desses termos na Educação Matemática, nas últimas décadas, tem tido diferentes abordagens. Isso evidencia o quão profícuo podem ser as pesquisas em que se toma a MM na perspectiva da Educação Matemática como objeto de estudo ou como referência para obtenção de dados empíricos.

Para Bassanezi (2013, p. 20), um modelo refere-se a "um conjunto de símbolos e relações matemáticas que representam de alguma forma o objeto estudado". A MM é entendida por esse autor como "processo dinâmico utilizado para a obtenção e validação de modelos matemáticos e [...] consiste na arte de transformar situações da realidade em problemas matemáticos cujas soluções devem ser interpretadas na linguagem usual” (BASSANEZI, 2003, p. 24).

Biembengut (2014) compreende o processo de modelagem, de modo semelhante à Bassanezi (2013), ou seja, como o processo envolvido na elaboração de modelo de qualquer área do conhecimento,

trata-se de um processo de pesquisa. A essência deste processo emerge na mente de uma pessoa quando alguma dúvida genuína ou circunstância instigam-na a encontrar uma melhor forma para alcançar uma solução, descobrir um meio para compreender, solucionar, alterar, ou ainda, criar ou aprimorar algo. E em especial, quando a pessoa tem uma percepção que instiga sua inspiração (p. 21). 
Já em relação à $\mathrm{MM}$, a autora compreende como o processo envolvido na elaboração de um modelo matemático entendendo-o como "um conjunto de símbolos os quais interagem entre si representando alguma coisa. [...] pode se dar por meio de desenho ou imagem, projeto, esquema, gráfico, lei matemática, dentre outras formas" (BIEMBENGUT, 2014, p. 20). A adaptação do processo de MM para o ensino de Matemática, ela denomina de Modelagem na Educação ou Modelação e entende como um método de ensino com pesquisa, considerando um determinado nível de ensino e um conteúdo a ser desenvolvido.

Para Barbosa (2008, p. 48), um modelo matemático é "qualquer outro tipo de registro matemático escrito que se refira à situação-problema, como as operações matemáticas básicas". No entendimento desse autor, a MM, na perspectiva da Educação Matemática, é entendida como um ambiente de aprendizagem, em que "os alunos são convidados a questionar ou investigar situações com referência na realidade por meio da Matemática" (BARBOSA, 2008, p. 48). Ainda é destacado que para que uma atividade seja definida ou não como MM, o problema não deve possuir estratégias de resolução prontas e deve ter referência com o dia a dia do aluno.

A definição de MM é apresentada por Burak (1992) como uma metodologia de ensino, ou seja, é "um conjunto de procedimentos cujo objetivo é construir um paralelo para tentar explicar matematicamente, os fenômenos presentes no cotidiano do ser humano, ajudando-o a fazer predições e tomar decisões" (p. 62).

O modelo matemático, para Almeida, Silva e Vertuan (2012, p. 12) pode ser entendido como uma "representação simplificada da realidade sob a ótica daqueles que a investigam. Sua formulação, todavia, não tem um fim em si só, mas visa fomentar a solução de algum problema". Esses autores consideram a MM uma alternativa pedagógica a qual pode ser descrita "em termos de uma situação inicial (problemática), de uma situação final desejada (que representa uma solução para a situação inicial) e de um conjunto de procedimentos e conceitos necessários para passar da situação inicial para a situação final" (ALMEIDA, SILVA e VERTUAN, 2012, p. 12).

Do exposto, denotamos que os diferentes entendimentos acerca da MM na Educação Matemática partem do pressuposto da compreensão e solução de um problema, valendo-se para isso da utilização da Matemática. Em relação à obtenção do modelo matemático que representa a situação investigada, Barbosa (2006) enfatiza que a ênfase das tarefas de Modelagem está na compreensão crítica dos significados da Matemática no contexto geral da sociedade e não necessariamente na obtenção do modelo matemático. Entretanto, para os demais autores 
apresentados, se perpassa pela escolha do tema, elaboração do modelo e validação desse modelo e há concordância quanto à origem do assunto a ser modelado que deve partir da realidade e interesse dos estudantes.

Esses diferentes entendimentos evidenciados pelos precursores da MM na Educação Matemática e pesquisadores emergem de suas formações e experiências e são influenciados pelo contexto sociogeográfico e cultural no qual as pesquisas são desenvolvidas.

Em relação à inserção dos fundamentos da MM na Educação Matemática na sala de aula, Bassanezi (2013) apresenta alguns obstáculos denominados de: obstáculos instrucionais, no qual ele denota que o processo de MM é demorado, logo não se consegue cumprir o programa (currículo) estabelecido; obstáculos para os estudantes uma vez que o envolvimento em atividades de MM foge da rotina deles, os quais não estão acostumados com esse processo; obstáculos para os professores que sentem-se inseguros pela possibilidade de se depararem com situações que desconhecem.

Alguns desses obstáculos apresentados por Bassanezi (2013) também foram destacados por Barbosa (2004) ao referir-se à formação de professores. O autor aborda três aspectos referentes às dificuldades dos professores ao conduzir atividades de MM no contexto da sala de aula: falta clareza sobre a operacionalização das atividades de $\mathrm{MM}$, pois os programas já estão estabelecidos; dúvidas para conduzir as atividades e falta de clareza da reação dos alunos, colegas de trabalho e pais frente à proposta.

Ainda, conforme Biembengut (2014), dificuldades referentes à inserção da MM na sala de aula estão vinculadas à formação inicial do professor, já que são poucas as disciplinas que efetivamente permitem aos acadêmicos o desenvolvimento de atividades de MM nos cursos de Licenciatura em Matemática e, além disso, quando tais disciplinas existem a carga horária é insuficiente para ensinar o estudante modelar. Outro ponto destacado pela autora refere-se aos cursos de formação continuada que apresentam pouco tempo para o professor se envolver em atividades de MM.

Em relação à formação continuada, Imbernón (2010, p. 115) considera como "toda intervenção que provoca mudanças no comportamento, na informação, nos conhecimentos, na compreensão e nas atitudes dos professores em exercício". Acreditamos na formação que se aproxima da escola e que tenha como ponto de partida os problemas advindos do contexto de trabalho dos professores; que seja um espaço/tempo que considere as demandas deles, as suas 
dificuldades, os seus anseios e que permita dar voz ao professor para compartilhar suas experiências as quais podem ser (re)significadas no coletivo e tornarem-se fonte de desenvolvimento profissional.

Entendemos desenvolvimento profissional como um "processo dinâmico e evolutivo da profissão docente, que inclui tanto a formação inicial quanto a permanente, englobando os processos que melhoram o conhecimento profissional, as habilidades e as atitudes" (IMBERNÓN, 2010, p. 45); que é "contínuo, composto pelo conjunto de circunstâncias, fatos, histórias pessoais e profissionais, atividades formais e informais que constituem a carreira docente" (GARCIA e PRYJMA, 2013, p. 43); envolve um movimento contínuo de transformação e constituição do sujeito dentro de um campo profissional específico (FIORENTINI e CRECCI, 2013),

que se inicia muito antes da formação inicial e que se estende durante toda a trajetória do professor, ou seja, se preocupa menos com o produto que com o processo que se desenrola por meio de um contínuo movimento de dentro para fora, valorizando o professor pelo seu potencial, no qual a prática é a base pra um relacionamento dialético entre teoria e prática e, muitas vezes, ponto de partida. (FERREIRA, 2003, p. 35).

Ao encontro dessa concepção, Nóvoa (1995) aponta que os cursos de formação não devem estar centrados em acumulação de conhecimentos e/ou técnicas, mas sim em cursos que desenvolvam um trabalho de reflexividade crítica do trabalho docente e reconstrução permanente da identidade do professor, de modo que o professor seja protagonista da formação.

Em relação à abordagem da Modelagem na formação inicial e continuada, é ponto de convergência entre os pesquisadores a necessidade da vivência do processo de Modelagem pelos professores, a fim de que se sintam encorajados a levar os fundamentos dessa tendência da Educação Matemática para sala de aula. Conforme Barbosa (2004, p. 7), "não basta o docente ter a experiência-própria como aluno, mas é preciso também que a tenha na perspectiva de professor". Assim, o autor sugere que a formação dos professores em relação à Modelagem diz respeito a dois domínios: a experiência como aluno que se constitui no desenvolvimento de diferentes atividades de modelagem e a experiência como professor que implica a discussão das tarefas do professor e refere-se à organização e condução das atividades na sala de aula.

Para Almeida, Silva e Vertuan (2012) e Dias (2005), no âmbito da formação, é conveniente o professor "aprender sobre" Modelagem, "aprender por meio" da Modelagem e "ensinar usando" a Modelagem, ou seja, os autores apresentam a necessidade de estudos teóricos sobre os 
fundamentos da Modelagem, da realização de vivências de Modelagem enquanto aluno e enquanto professor. Todavia, não se tem garantias que mesmo após ter vivenciado o processo de Modelagem na formação inicial ou continuada, os professores a tomem como parte de suas ações rotineiras na sala de aula. Isso já foi mencionado na pesquisa de Oliveira (2010). A autora destaca que as experiências com modelagem, vivenciadas pelos professores, não implicam que esses profissionais passem a utilizá-la em suas práticas escolares.

A partir do exposto propomos a realização deste estudo, a fim de melhor reconhecer as pesquisas que tratam da Modelagem Matemática na perspectiva da Educação Matemática e Formação Continuada de professores, bem como compreender a partir delas o desenvolvimento profissional (DP) dos professores.

\section{Abordagem metodológica}

Considerando o objetivo desta pesquisa, a classificamos como sendo de natureza qualitativa, do tipo bibliográfica, a qual conforme Minayo (2001, p. 53) "coloca frente a frente os desejos do pesquisador e os autores envolvidos em seu horizonte de interesse". Na pesquisa qualitativa, o pesquisador é um instrumento da investigação "ao observar ações e contextos e, com frequência, ao desempenhar intencionalmente uma função subjetiva no estudo, utilizando sua experiência pessoal em fazer interpretações" (STAKE, 2011, p. 30).

A busca pelas pesquisas realizadas se deu no portal do Instituto Brasileiro de Informação em Ciência e Tecnologia (IBICT), o qual possibilitou a identificação das dissertações e teses produzidas entre 2010 e 2019. Para tal, utilizamos as expressões Formação Continuada e Modelagem Matemática no campo busca avançada com a intenção de identificar as pesquisas que traziam as expressões mencionadas no título. A partir disso, encontramos quatorze pesquisas, dentre as quais selecionamos nove dissertações e duas teses para análise. As pesquisas selecionadas constam no Quadro 1, a seguir.

Quadro 1: Pesquisas brasileiras sobre Formação Continuada e MM

\begin{tabular}{|cccccc|}
\hline Ano & $\mathbf{N}^{\mathbf{0}}$ & Título & $\begin{array}{c}\text { Tipo de } \\
\text { Pesquisa }\end{array}$ & Sigla & IES / Estado \\
\hline \multicolumn{2}{|c|}{$\begin{array}{c}\text { Modelagem Matemática na Educação } \\
\text { Matemática: Contribuições e Desafios à } \\
\text { Formação Continuada de Professores na } \\
\text { Modalidade Educação a Distância Online }\end{array}$} & Dissertação & D1 & $\begin{array}{c}\text { Universidade } \\
\text { Estadual de Ponta } \\
\text { Grossa / PR }\end{array}$ \\
\hline
\end{tabular}




\begin{tabular}{|c|c|c|c|c|c|}
\hline 2011 & 2 & $\begin{array}{c}\text { A prática de Modelagem Matemática } \\
\text { como um cenário de investigação na } \\
\text { formação continuada de Professores de } \\
\text { Matemática }\end{array}$ & Dissertação & D2 & $\begin{array}{l}\text { Universidade } \\
\text { Federal de Ouro } \\
\text { Preto/MG }\end{array}$ \\
\hline \multirow{3}{*}{2016} & 3 & $\begin{array}{l}\text { Formação Continuada de Professores } \\
\text { em Modelagem Matemática na } \\
\text { Educação Matemática: O Sentido que os } \\
\text { Participantes Atribuem ao Grupo. }\end{array}$ & Dissertação & D3 & $\begin{array}{l}\text { Universidade } \\
\text { Estadual do Oeste } \\
\text { do Paraná/PR. }\end{array}$ \\
\hline & 4 & $\begin{array}{l}\text { Práticas Pedagógicas de Professores da } \\
\text { Educação Matemática Básica num } \\
\text { Contexto de Formação Continuada em } \\
\text { Modelagem Matemática na Educação } \\
\text { Matemática. }\end{array}$ & Dissertação & D4 & $\begin{array}{c}\text { Universidade } \\
\text { Estadual do Oeste } \\
\text { do Paraná/PR }\end{array}$ \\
\hline & 5 & $\begin{array}{c}\text { Modelagem Matemática e Mobilização } \\
\text { de Conhecimentos Didático-Matemáticos } \\
\text { na Formação Continuada de Professores } \\
\text { dos Anos Iniciais. }\end{array}$ & Tese & $\mathrm{T} 1$ & $\begin{array}{l}\text { Universidade } \\
\text { Federal de São } \\
\text { Carlos/SP }\end{array}$ \\
\hline \multirow{3}{*}{2017} & 6 & $\begin{array}{c}\text { O Sentido da Formação Continuada em } \\
\text { Modelagem Matemática na Educação } \\
\text { Matemática desde os Professores } \\
\text { Participantes. }\end{array}$ & Dissertação & D5 & $\begin{array}{c}\text { Universidade } \\
\text { Estadual do Oeste } \\
\text { do Paraná/PR }\end{array}$ \\
\hline & 7 & $\begin{array}{c}\text { Concepções Prévias de Professores e } \\
\text { Formação Continuada em Modelagem } \\
\text { Matemática. }\end{array}$ & Dissertação & D6 & $\begin{array}{l}\text { Universidade } \\
\text { Estadual do Oeste } \\
\text { do Paraná/PR }\end{array}$ \\
\hline & 8 & $\begin{array}{l}\text { (Re)configurações do Agir Modelagem } \\
\text { na Formação Continuada de Professores } \\
\text { de Matemática da Educação Básica. }\end{array}$ & Tese & $\mathrm{T} 2$ & $\begin{array}{c}\text { Pontifícia } \\
\text { Universidade } \\
\text { Católica do Rio } \\
\text { Grande do Sul/RS }\end{array}$ \\
\hline 2018 & 9 & $\begin{array}{c}\text { Formação Continuada em Modelagem } \\
\text { Matemática em Contexto de Pesquisa: } \\
\text { Um Estudo a partir dos Professores } \\
\text { Participantes. }\end{array}$ & Dissertação & D7 & $\begin{array}{l}\text { Universidade } \\
\text { Estadual do Oeste } \\
\text { do Paraná/PR }\end{array}$ \\
\hline \multirow[b]{2}{*}{2019} & 10 & $\begin{array}{l}\text { Metapesquisa dos referenciais teóricos } \\
\text { de textos sobre formação continuada de } \\
\text { professores em modelagem matemática }\end{array}$ & Dissertação & D8 & $\begin{array}{l}\text { Universidade } \\
\text { Estadual do Oeste } \\
\text { do Paraná/PR }\end{array}$ \\
\hline & 11 & $\begin{array}{l}\text { Um olhar sobre a própria prática com } \\
\text { modelagem matemática na educação } \\
\text { matemática ao estar-com-um-grupo de } \\
\text { formação continuada }\end{array}$ & Dissertação & D9 & $\begin{array}{l}\text { Universidade } \\
\text { Estadual do Oeste } \\
\text { do Paraná/PR }\end{array}$ \\
\hline
\end{tabular}

Fonte: Elaboração das Autoras

A análise dos dados é realizada por meio dos procedimentos de análise de conteúdo que, 
conforme Minayo (2001), abrange três fases: pré-análise, exploração do material e tratamento dos resultados obtidos e interpretação. Na primeira fase organizamos o material a ser analisado e definimos as unidades de registro, as quais se referem aos elementos obtidos por meio da decomposição do conjunto da mensagem. Conforme a autora,

\begin{abstract}
podemos utilizar a palavra como uma unidade, trabalhando com todas as palavras de um texto ou com apenas algumas que são destacadas de acordo com a finalidade do estudo. A frase ou a oração também são outros exemplos de unidade de registro. Outra unidade é o tema que se refere a uma unidade maior em torno da qual tiramos uma conclusão. Esse tipo de unidade é uma das modalidades mais utilizadas por aqueles que empregam a análise de conteúdos (MINAYO, 2001, p. 75).
\end{abstract}

Para a exploração do material realizamos a leitura das pesquisas selecionadas e buscamos reconhecer os objetivos, os procedimentos de constituição e análise de dados, as referências teóricas adotadas, os participantes e perspectivas de continuidade das pesquisas. A partir disso, buscamos identificar o que é recorrente a partir dessas unidades temáticas. Esse processo envolve inúmeras leituras e releituras e culmina com a construção das categorias, as quais estabelecem classificações e agrupam ideias. Por fim, na terceira fase explicitamos os resultados e a interpretação do processo realizado.

\title{
4 Resultados e Discussão
}

Apresentamos nesta seção os resultados e discussões advindos da análise realizada em duas subseções: 1) reconhecimento das pesquisas e 2) o desenvolvimento profissional dos professores participantes das formações nas pesquisas analisadas.

\subsection{Reconhecimento das pesquisas}

A partir da leitura na íntegra das produções selecionadas, destacamos que os objetivos das pesquisas, embora tenham como contexto a formação continuada, possuem focos diferentes. Dentre as pesquisas analisadas, em relação aos objetivos: observamos que $(2: 11)^{2}$ possuem como foco de investigação o sentido atribuído à formação continuada pelos professores participantes (D3, D5); (1:11) possui como foco a compreensão de como a Modelagem Matemática desenvolvida num curso na modalidade EaD pode contribuir para a superação das dificuldades do

\footnotetext{
2 Frequência dos trabalhos - "2 dos 11 trabalhos analisados"
} 
professor no entendimento da metodologia e na sua utilização em sala de aula (D1); (2:11) possuem como foco a prática docente: o que é revelado sobre as práticas pedagógicas dos professores participantes da formação em modelagem (D4) e as (re)configurações do trabalho do professor com modelagem a partir da formação continuada (T2); (2:11) apresentam como foco a compreensão dos professores acerca da formação continuada com Modelagem (D6, D7); (2:11) objetivam identificar as contribuições da Modelagem para a formação continuada de professores de Matemática (D2) e perceber como a interação pode proporcionar a aproximação da Modelagem e a sua implementação em sala de aula (D9); (1:11) tem como foco a discussão do conhecimento didático matemático com professores dos Anos Iniciais a partir das atividades de modelagem (T1); e (1:11) busca compreender o que se mostra dos referenciais teóricos utilizados nos artigos sobre formação continuada de professores em Modelagem nos periódicos da área (D8).

A constituição dos dados das pesquisas deu-se em (6:11) por meio de gravações em áudio dos encontros e sua posterior transcrição (D3, D4, D5, D6, D2 e D9); (5:11) análise dos diários produzidos pelos professores participantes (D3, D4, D5, D6, D9); (5:11) depoimento individual dos professores os quais foram gravados e transcritos, entrevistas e questionários (D1, D2, D3, D5 e D7); (1:11) observação das aulas dos professores participantes com o uso do diário de campo (D6); (1:11) textos sobre formação continuada de professores em modelagem das últimas sete edições da Conferência Nacional sobre Modelagem na Educação Matemática — CNMEN (D8); e (1:11) uso de fórum de debates, chats, ferramenta wiki da Plataforma Moodle (D1). Portanto, com exceção da $\mathrm{D} 8$, todas as demais pesquisas constituíram dados empíricos a partir da realização de práticas de modelagem com os professores participantes.

Quanto ao tipo de pesquisa, (7:11) apresentam a pesquisa fenomenológica e para a análise dos dados utilizaram o software Atlas ti, a partir do qual são estabelecidas as unidades de significados conforme o objetivo da pesquisa (D3, D4, D5, D6, D7, D8 e D9). Após as asserções presentes nas unidades de significado, são constituídas categorias abertas e essas categorias emergentes da redução fenomenológica, são apresentadas nos resultados.

Em relação às teses, a produção dos dados em T1 configurou-se pela triangulação. Para isso, foi utilizado o método da observação, no qual uma aluna da graduação exerceu o papel de observador cego - participou da formação, realizando observações, sem o conhecimento da hipótese e dos objetivos da pesquisa -; utilizou-se o caderno de anotações produzido sempre após o término dos encontros com as professoras; recurso da filmagem e o gravador para captar 
as falas dos participantes; questionários com questões fechadas para caracterizar as professoras participantes e questões abertas para possibilitar a expressão de avaliações acerca da problemática da pesquisa. A pesquisa T1 também é de cunho qualitativo, do tipo pesquisa-ação. A análise dos dados se deu por meio das categorias do Conhecimento Didático-Matemático proposta por Juan Godino ${ }^{3}$ e seus colaboradores.

A tese T2 tem como instrumentos de constituição de dados a gravação em áudio de todos os encontros de formação continuada, os diários de campo da professora formadora/pesquisadora e a escrita dos diários dos encontros de formação, de planejamento e de implementação das tarefas de MM na Educação Matemática de uma professora participante da formação continuada. A pesquisa é cunho qualitativo, do tipo estudo de caso. A análise de dados se deu por meio do Interacionismo Sociodiscursivo (ISD) proposto por Jean Paul Bronckart ${ }^{4}$ e seus colaboradores, compreendendo a análise do contexto de produção e dos níveis de análise textual organizacional, enunciativo e semântico. Observou-se que esta pesquisa se utilizou como método de análise dos textos produzidos procedimentos advindos da linguística aplicada.

Quanto aos participantes das pesquisas, (8:11) trabalharam com professores de Matemática da Educação Básica - Anos Finais do Ensino Fundamental e Ensino Médio - de municípios próximos do local em que se realizava a formação (D1, D2, D3, D4, D5, D6, D9 e T2); (1:11) teve participação de professores do Ensino Superior (D2). Há também (1:11) cujos participantes foram os professores que participaram de formação continuada no âmbito de pesquisas já realizadas em nível scricto sensu (D7) e (1:11) teve como foco os professores dos Anos Inicias, assinalando possibilidades de maior desenvolvimento de pesquisas nesse nível de ensino (T1).

Em relação ao contexto das formações realizadas, observamos que (5:11) tem como foco o projeto de extensão "Formação Continuada de Professores em Modelagem Matemática na Educação Matemática", vinculado ao grupo de pesquisa Formação de Professores de Ciências e Matemática, na linha de pesquisa "Tendências, Modelagem Matemática e Fenomenologia", coordenado pelo Professor Doutor Tiago Emanuel Klüber (D3, D4, D5, D6 e D9). O projeto também previa que a formação ocorresse em escolas estaduais, nas quais os formadores atuavam como professores da Educação Básica, e desse modo, estariam inseridos na formação como 
professores em formação — formadores/formandos e não somente como formadores.

O modelo de formação proposto está vinculado à proposta de modelo misto de García (1999). Este autor entende que a formação continuada "representa comum encontro entre pessoas adultas, uma interação entre formador e formando, com uma intenção de mudança, desenvolvida num contexto organizado e institucional mais ou menos delimitado" (GARCÍA, 1999, p. 22).

A descrição dos encontros de formação realizados acontece em (4:11) pesquisas (D3, D4, D5 e D6), nas quais as ações de extensão são estruturadas em quatro fases: a primeira fase é a introdução do projeto, apresentação dos professores envolvidos e ao mesmo tempo momento de compartilhar os constructos pessoais dos professores. A segunda fase compreende a inserção no contexto das atividades de MM a partir da dinâmica interna do grupo, desenvolvendo atividades simuladas com os professores participantes do grupo. Na terceira fase ocorre aprofundamento teórico sobre MM, oportunizando reflexão e discussão. Na quarta fase abordam-se experiências pedagógicas com a MM seguidas de reflexões sistemáticas sobre a própria ação, com objetivo de incentivar a realização de práticas de MM em sala de aula e posterior socialização com os colegas da experiência vivida. Observamos, ainda, que (1:11) apresenta brevemente as atividades realizadas para mostrar a sua participação no grupo que segue as etapas acima descritas (D9).

Observamos que em (1:11) o que denominou-se de formação continuada aconteceu em uma disciplina eletiva do Mestrado Profissional em Educação Matemática da Universidade Federal de Ouro Preto (D2), a qual foi realizada no segundo semestre de 2010 e além dos nove alunos regularmente matriculados, seis eram professores de Matemática de diferentes níveis de ensino que cursavam como disciplina isolada.

Ainda, quanto às formações realizadas, (1:11) realizou um curso totalmente a distância, realizado na Plataforma Moodle (D1). O curso compreendeu três fases: 1) discussão de aspectos teóricos sobre a MM a fim de instrumentalizar os professores na utilização da Plataforma Moodle e debater sobre as diferentes perspectivas de MM e a perspectiva assumida no curso; 2) atividade de MM entre os professores a qual teve como finalidade familiarizá-los com todas as etapas de uma atividade de $\mathrm{MM}$; 3 ) refere-se à atividade de $\mathrm{MM}$ desenvolvida pelos professores junto a seus alunos.

Já quanto às teses, (1:11) propôs um curso de extensão com carga horária de 40 horas, tendo como base a discussão de artigos científicos e a realização de uma atividade envolvendo MM na qual os professores participantes deveriam buscar informações a fim de solucionar 0 
problema proposto (T1). Em T2, as ações são vinculadas a um programa de extensão e houve a proposição aos professores do grupo de formação de encontros mensais para o estudo dos fundamentos da MM na Educação Matemática. A pesquisa assumiu a concepção de Biembengut $(2014,2016)$. Assim, os professores vivenciaram tarefas de Modelagem Matemática e Modelagem na Educação; estudaram, planejaram em grupos a adaptação do processo de MM, implementaram em sala de aula com os estudantes e realizaram a escrita dos diários - formação e planejamento — das atividades realizadas. Em relação à T2, destacamos o entrelaçamento dos fundamentos da MM na Educação Matemática e o do aporte teórico-metodológico e analítico do Interacionismo Sociodiscursivo para compreender o trabalho do professor de Matemática com Modelagem, ao que a autora denominou de agir modelagem.

Quanto às perspectivas de continuidade, (6:11) assinalam que o grupo de estudos continuará a reunir-se para debater e planejar assuntos pertinentes ao contexto escolar dos professores (D3, D4, D5, D6, D9 e T2). Percebeu-se também que (2:11) são pesquisas nas quais os dados empíricos foram obtidos a partir do mesmo grupo de formação continuada (D3, D4). Em T2 destaca-se que a formação continuada é realizada com os professores desde o ano de 2010 e o grupo de formação mantém encontros periódicos. Já (3:11) não apontaram para a perspectiva de continuidade do curso de formação (D1, D2 e T1).

Do exposto, podemos considerar, de modo geral, que os cursos de formação continuada foram organizados para favorecer aos professores o estudo dos pressupostos teóricos da MM e a inserção desta tendência temática da Educação Matemática na sala de aula dos professores participantes. Nesse sentido, destacamos que das 11 pesquisas estudadas percebemos a transição da formação continuada para a sala de aula dos professores participantes em (5:11): D3, D4, D6, D9 e T2. Isso é apresentado nas pesquisas de diferentes maneiras: o professor reorganiza as atividades da formação e implementa na sala de aula, valendo-se inclusive das mesmas temáticas (D3, D4, D6, D9 e T2); os professores planejam conjuntamente a atividade para levar para sala de aula de modo que o estudante seja o protagonista, ou seja, deixando a escolha do tema, a busca por informações sobre o tema e a formulação do problema por conta deles (D6). Discutimos a transição da formação continuada para a sala de aula, na próxima subseção, como um indicativo de desenvolvimento profissional dos professores participantes das formações. 


\subsection{0 desenvolvimento profissional dos professores participantes da formação nas pesquisas analisadas}

O estudo desenvolvido por Passos et al. (2006) destaca os contextos de prática pedagógica nos quais os professores possam experienciar, perceber e comprovar a eficácia de outras formas de ensinar Matemática como catalisadores de desenvolvimento profissional. Nessa mesma perspectiva, Fiorentini e Crecci (2013) entendem que os professores aprendem e se desenvolvem profissionalmente por meio da participação de diferentes práticas e contextos, e destacam que o desenvolvimento profissional é um processo "contínuo de transformação e constituição do sujeito, ao longo do tempo" (p. 13).

A partir do entendimento dos autores supracitados, apresentamos nesta subseção nossas compreensões acerca do desenvolvimento profissional dos professores participantes das formações, por meio das quais foram constituídos os dados empíricos das pesquisas analisadas, a partir de duas categorias: na primeira categoria buscamos compreender a formação continuada na perspectiva de desenvolvimento profissional e o contexto das formações como espaço/tempo de desenvolvimento profissional; na segunda categoria discutimos a transição da formação continuada para a sala de aula e as reflexões dos professores acerca do trabalho com modelagem demarcando um movimento importante das formações realizadas e caracterizando esse movimento como uma marca de desenvolvimento profissional. 0 Quadro 2, a seguir, sintetiza 0 movimento de análise.

Quadro 2: Síntese do DP a partir das pesquisas analisadas

\section{O DP a partir das pesquisas analisadas}

\begin{tabular}{l|l}
$\begin{array}{l}\text { Formação continuada na perspectiva de DP e } \\
\text { contexto das formações como o espaço/tempo } \\
\text { de DP }\end{array}$ & $\begin{array}{l}\text { Transição da formação continuada para a sala } \\
\text { de aula }\end{array}$ \\
\hline
\end{tabular}

As formações favorecem momentos de reflexão Denota DP situado no fazer docente. sobre o trabalho docente, sobre teorias de ensino, a fim de provocar transformações na prática.

As formações favorecem o trabalho de modo colaborativo.

As formações se aproximam do contexto da escola e consideram os problemas do cotidiano dos professores
Os momentos de socialização do desenvolvimento da prática de modelagem no grupo denotam aprendizagem docente.

A implementação de práticas de modelagem potencializa reflexões sobre 0 seu desenvolvimento e revelam as dificuldades dos professores. 
Observamos que todas as dissertações e teses tiveram como contexto a realização de cursos de formação continuada e a expressão desenvolvimento profissional - tomada como unidade de análise — surge 127 vezes nas 11 pesquisas estudadas: D1(2), D2(1), D3(11), D4 (30), D5(5), D6(8), D7(6), D8(48), D9(5), T1(4) e T2(7).

De modo geral, encontramos nas pesquisas analisadas a concepção de formação continuada na perspectiva de desenvolvimento profissional do professor e o contexto das formações como espaço/tempo de desenvolvimento profissional, ou seja, as formações com Modelagem realizadas proporcionaram momentos para os professores refletirem sobre o seu trabalho e suas teorias de ensino, a fim de provocar transformações na prática (D1, D3, D4, D7, D8, T2). O exposto é apontado por diferentes autores como elemento importante de desenvolvimento profissional: Fiorentini et al. (2002, p. 153) apresentam o movimento de reflexão sobre a prática docente ao textualizarem que "a reflexão, a investigação da própria prática e os saberes da experiência" são elementos fundamentais para a constituição e o desenvolvimento profissional do professor; para Garcia (1999, p. 153), há a necessidade do desenvolvimento nos professores de competências metacognitivas que lhes "permitam conhecer, analisar, avaliar e questionar a sua própria prática docente"; e Ponte (2014), ao considerar que processos de formação que propiciem momentos de reflexão promovem o desenvolvimento profissional dos professores. Isso está marcado nas pesquisas analisadas conforme as passagens, a seguir.

Nessa perspectiva, os professores fazem referência à necessidade de redirecionar 0 foco de suas práticas pedagógicas, dirigidas quase que exclusivamente ao ensino e à reprodução para a aprendizagem dos alunos [...] (D4, p. 144, grifos nossos).

[...] o professor manifesta um interesse pela busca de formação para mudar suas aulas, também, uma busca por métodos diferenciados para mudar sua prática e aprender mais sobre como fazer Modelagem com o formador para ganhar segurança com essa tendência (D7, p. 109, grifos nossos).

[...] observaram-se projeções da professora, no sentido de favorecer maior interação dos estudantes e ser menos transmissiva, sinalizando para uma tomada de consciência sobre seu agir docente e projeção de transformação desse agir (T2, p. 198, grifos nossos).

É importante ressaltar o relato de que a partir da formação em Modelagem Matemática, os participantes começaram a repensar como ensinar, como fazer diferente, relacionando os conteúdos com o cotidiano dos alunos. Uma visão que propiciou olhar para o que o aluno sabe e repensar a ideia de que o aluno aprende com explicação no quadro e de forma individual - maneira tradicional de ensino (D5, p. 14, grifos nossos)

As pesquisas estudadas apontaram o trabalho em grupo de modo colaborativo como positivo para o desenvolvimento profissional (D3, D4, D7, D8, D9, T2). A noção de que trabalho em grupo de modo colaborativo, envolvendo parceria entre professores universitários e 
professores da educação básica favorece o desenvolvimento profissional dos professores é apontada por diferente autores: Fiorentini et al. (2002), Ponte et al. (2014) e Imbernón (2010) e foi percebida nas pesquisas analisadas. Para Imbernón (2010),

a formação continuada requer um clima de colaboração entre os professores, sem grandes reticências ou resistências (não muda quem não quer mudar ou não se questiona aquilo que se pensa que já vai bem), uma organização minimamente estável nos cursos de formação de professores (respeito, liderança democrática, participação de todos os membros), que dê apoio à formação, e a aceitação de uma contextualização e de uma diversidade entre os professores que implicam maneiras de pensar e agir diferentes (p. 31).

Além disso, em ambientes colaborativos os professores podem compartilhar experiências e problematizar seus conhecimentos levando à produção de novas aprendizagens relativas aos diferentes contextos do seu trabalho. 0 exposto foi evidenciado nas pesquisas estudadas conforme as passagens apresentadas seguir.

As unidades pertencentes a essa categoria revelam o exemplo e o apoio dos pares como um fator mencionado pelos professores participantes da Formação como constituinte de suas práticas pedagógicas (D4, p. 170, grifos nossos).

A professora textualizou a compreensão e colaboração dos colegas como algo positivo (T2, p. 211, grifos nossos).

A categoria aberta congrega sentidos sobre o sentimento dos professores e as características do trabalho em grupo, inseridos no contexto de formação em Modelagem, exibindo dentre outros aspectos, a satisfação em participar do grupo; 0 compromisso com o grupo; o sentimento de parceria entre os colegas e a troca de experiências entre os participantes (D3, p.88, grifos nossos).

No movimento de estar-com-o-grupo de formação, a professora acompanha os momentos em que o grupo seleciona e revisa as atividades que serão implementadas nas Formações em Ações Descentralizadas. Ela percebe que o diálogo é uma característica marcante no relacionamento entre os participantes do grupo de formação. Reconhece a importância do trabalho coletivo para o planejamento das ações desenvolvidas (D8, p.88, grifos nossos).

Além do exposto, nas pesquisas analisadas encontramos a noção de que a formação deve se aproximar da escola e considerar os problemas advindos do contexto de trabalho dos professores de modo que os professores se sintam protagonista da formação (D4, D8 T2), conforme preconiza Imbernón (2010).

Em contrapartida, a partir da compreensão das unidades, há um interesse dos professores em buscar mais formação, em aprender mais sobre (D7, p. 104, grifos nossos).

Implicitamente, no caso dos professores participantes da formação, eles percebem que precisam estar se atualizando, vendo coisas novas, como por exemplo, 
metodologias diferentes, ferramentas para o ensino, textos sobre as tendências da Educação Matemática (D5, p 144, grifos nossos).

Quanto à questão da contextualização dos conteúdos matemáticos trabalhados em sala de aula com problemas da realidade dos alunos, os participantes foram unânimes em ressaltar a importância dessa conexão para a aprendizagem, especialmente por acreditarem que isso permitiria aos alunos perceberem a relação da Matemática escolar com a Matemática presente em seu cotidiano, como podemos destacar (D2, p. 86, grifos nossos).

A segunda categoria retrata a transição da formação continuada para a sala de aula e as reflexões dos professores acerca do trabalho com Modelagem. Essa transição se deu em (5:11) pesquisas: D3, D4, D6, D9 e T2. Compreendemos esse movimento como uma marca de DP, visto que ao inserir as práticas de modelagem nas suas aulas, os professores efetivamente transformam o seu trabalho, ou seja, o que antes era apresentado como um desejo a partir da formação continuada e sinalizado na categoria apresentada anteriormente, se materializa na sala de aula, nas interações com os estudantes.

Ao inserir a MM no seu contexto específico de trabalho, os professores percebem a possibilidade de transformar o ensinar e o aprender Matemática e isso denota marca de DP situado no próprio fazer docente. A prática com modelagem permite 0 envolvimento do professor $\mathrm{e}$ proporciona a experiência concreta, a partir da qual se pode refletir sobre o seu desenvolvimento, o envolvimento dos alunos e as dificuldades apresentadas, dentre outros fatores.

[...] com o desenvolvimento da Modelagem em sala de aula, o professor começa a entender o "como fazer" (D7, p.93).

[...] os professores comentaram sobre a maneira como conduziriam essa escolha, optando por conduzi-la por temas de domínio dos docentes, dessa forma evitando que a atividade recaísse em algo irresolvível, que o professor não conseguisse conduzir a continuidade da atividade (D6, p. 74).

Alguns momentos foram tensos, pois a variedade de caminhos, muitos certos, outros nem tanto, e alguns que divergiam totalmente da ideia de solução, foi emergindo e aquela certa segurança das aulas com exercícios preestabelecidos não acontece numa aula com práticas de Modelagem Matemática (D9, p. 64).

Observamos que em (5:11) há o relato dos professores que desenvolveram a atividade de modelagem em nível do Ensino Fundamental e/ou Ensino Médio com o auxílio dos professores formadores e participantes das ações de formação continuada (D3, D4, D6, D9 e T2). As atividades desenvolvidas com os estudantes foram (re)organizadas a partir da formação continuada e algumas com proposições de novos temas, diferentes dos trabalhados nas formações. Destacamos, conforme Imbernón (2010, p. 33), que "para introduzir certas formas de trabalho na sala de aula é fundamental que os professores sejam apoiados por seus colegas ou por um 
assessor externo durante as aulas" e isso está assinalado nas pesquisas analisadas, conforme as passagens apresentadas a seguir:

0 apoio dos professores formadores-formandos aos colegas do grupo, as unidades mostram que os professores formandos-formadores se sentem motivados por esses professores a realizar as atividades de Modelagem Matemática, pois recebem apoio desde a parte estrutural das atividades, bem como auxilio emocional (D3, p.87).

Outros professores relataram que estavam preparando outras atividades para aplicarem em suas turmas, mas que necessitavam do apoio do grupo para terminar de elaborar e, se possível, auxiliar na aplicação (D4, p. 81).

As vinte e seis unidades de significado [...] demonstram que, para a implementação da Modelagem em sala de aula pelos professores, é fundamental a interação dos colegas de trabalho, o apoio e o comprometimento dos gestores e das famílias dos alunos (D7, p 93).

Observamos que após a realização da prática de modelagem com os alunos, os professores participantes das formações socializavam as suas experiências nos encontros subsequentes (D3, D4, D6, D9 e T2).

Em D6 a atividade foi planejada de modo a deixar os estudantes responsáveis pela escolha do tema, pesquisa exploratória sobre o tema e formulação do problema, a qual contou com auxílio dos professores participantes da formação continuada. Após o desenvolvimento com os alunos, realizou-se no grupo de formação reflexões acerca da participação dos alunos na atividade, dificuldades e tempo de planejamento. De modo semelhante, em D3, D4, D9 e T2 também aconteceu a socialização das atividades de modelagem realizadas com os estudantes da educação básica no grupo de formação e a produção de narrativas relatando a experiência realizada. Esse movimento de retornar ao grupo e contar sobre a experiência vivenciada apresenta potencialidades para promover a aprendizagem dos professores sobre o desenvolvimento do processo de modelagem na sala de aula e mostra-se como um contexto favorável para 0 desenvolvimento profissional, pois ao socializar sua experiência - embora cada professor tenha um contexto específico de trabalho - , ela deixa de ser apenas do sujeito que a textualiza. Ou seja, ao textualizar suas experiências com modelagem, oralmente ou por escrito, não aprende apenas quem narra sua história, mas também os interlocutores da história narrada (FIORENTINI e CRECCI, 2013). As passagens, a seguir, apresentam o movimento provocado pela socialização das experiências com modelagem no grupo em D3, D4, D9 e T2:

Um professor discorreu que com a ajuda de um professor formador-formando e um colega do grupo, adaptaram a atividade que foi desenvolvida no quinto encontro sobre a dengue, para uma atividade sobre a gripe H1N1. Essa foi desenvolvida em duas 
turmas do Ensino Médio também com parceria de um dos professores formadoresformandos (D3, p.81).

O professor relatou seu contentamento ao observar o empenho de seus alunos ao realizarem a atividade, chegando, inclusive, a irem a escola em horários diferentes dos seus de aula para fazer a coleta da água dispensada pelo ar-condicionado. disso, o professor ficou surpreso [...] com as distintas estratégias de resolução dos problemas apresentadas pelos seus alunos (D4, p. 119).

Ao estar-com-o-grupo, a professora percebe que uma atividade de Modelagem pode passar por ajustes para sua implementação em determinado ano/série levando em consideração o conhecimento dos estudantes, sem deixar de ser Modelagem em relação ao planejado e, se necessário, é possível realizar a prática em momentos distintos, a fim de estimular o diálogo entre as partes envolvidas. Ela toma uma decisão em adequar uma prática aos conhecimentos matemáticos da turma (D9, p. 92).

A colega Maria apresentou a prática de Modelagem Matemática sobre cubagem de madeira. Muito interessante! Tema que pode ser bastante explorado, temos muito ainda pra desenvolver sobre este assunto, ficou aberto para diversas possibilidades diferentes (T2, p. 297).

Do exposto, percebeu-se nas dissertações e nas teses que nem todos os professores participantes da formação continuada implementaram tarefas de MM em sala de aula, evidenciando que a transição da formação continuada para a sala de aula não se materializa de forma natural, mesmo contando com o apoio do formador/pesquisador/colega. Isso pode ser decorrente das dificuldades apontadas pelos professores e textualizadas nos encontros de formação referente ao trabalho com Modelagem e que já foram sinalizadas por Biembengut (2014), Bassanezi (2013) e Barbosa (2004).

No início do encontro, os professores argumentaram sobre os obstáculos quanto à inserção de atividades de Modelagem, identificados por eles no decorrer de nossos encontros, e na atividade que desenvolvemos com uma turma de ensino médio (D6, p. 74).

A discussão da baixa carga horária ou a ausência de trabalhos com MM na Educação Matemática na formação inicial ou continuada do professor se fez presente em (5:11), conforme denotam a passagens a seguir:

Os professores participantes do curso demonstraram preocupação com a falta de preparo para trabalhar com a MM em sala de aula e apontaram como causa a deficiência na formação inicial dos futuros professores de matemática e na formação continuada para os que já estão atuando em sala de aula (D1, p. 76).

Para a maioria deles o contato com essa tendência foi somente na formação inicial, contemplada em um único semestre com baixa carga horária, fato que para eles dificulta o reconhecimento de uma atividade de Modelagem (D3, p. 71).

O trabalho com a Modelagem, na formação inicial é mais informativo do que formativo, conforme revelam as unidades presentes a essa categoria, de modo que os futuros professores acabam tendo pouco conhecimento sobre ela (D4, p. 98). 
Além disso, em (2:11) foram apresentadas falas de seus participantes quanto à vivência e à utilização da MM na sala de aula, apontando a ausência desse processo durante a formação inicial, conforme mostram as passagens:

[...] o problema que encontro, e que muitas vezes impede esse trabalho são a falta de tempo para o preparo das aulas e também a insegurança que muitas vezes sentimos ao propor alguma atividade desse tipo devido à falta de formação que tivemos na universidade (D1, p. 76).

Ainda não seria capaz de trabalhar um projeto de modelagem (Professor grupo do táxi: PT1); Ainda não, pois acho que não fui preparado durante minha graduação (Professor grupo do combustível: PC2); Na minha formação acadêmica, não tive nenhuma disciplina que abordasse a modelagem (P Professor grupo do combustível: PC1) (D2, p. 85).

Outros aspectos já mencionados por Biembengut $(2014,2016)$ e Bassanezi (2013), como a insegurança para trabalhar atividades de MM na Educação Matemática na sala de aula, o tempo para planejamento e desenvolvimento com os alunos, a escolha do tema e até mesmo a dificuldade de visualização da MM no contexto escolar são também assinalados nas pesquisas analisadas e se fizeram presentes em (6:11), conforme evidenciam as passagens a seguir:

Os professores disseram que, a princípio, não trabalhariam com esta perspectiva, pois, poderia emergir temas que não dominassem (D6, p. 72).

0 professor avaliou a elaboração da atividade como difícil, haja vista que exigiu deles a realização de uma série de pesquisas (D4, p. 124).

Não conseguiram sentar com professores de outras áreas para planejar, [...] 0 fator tempo - que incomoda o professor no que diz respeito tanto à preparação de atividades de MM quanto no desenvolvimento das atividades com os alunos (D5, $\mathrm{p}$. 110).

Ficou evidente a dificuldade em elaborar os problemas e fazer as pesquisas dentro do tema (D1, p. 84).

A professora começa a perceber indicativos possiveis ideias para elaboração de atividades de Modelagem, porém deixa claro que ainda tem dificuldade em elaborar interrogações para investiga-las (D9, p. 86).

0 tema é sempre o meu problema. Como encontrar um tema, tudo me agrada ao mesmo tempo me assusta, o medo de não dar conta. 0 medo de meu aluno não captar o conteúdo envolvido (T2, p. 296).

Em relação ao cumprimento do currículo, (4:11) apontaram como dificuldade para inserção da MM na Educação Matemática na sala de aula: D1, D3, D6 e T2.

[...] terei que aplicar a atividade no contra turno com apenas um grupo de alunos, pois não me autorizaram a aplicar na turma normal. Argumentaram que vai atrasar 0 conteúdo, visto que este trabalho não consta do planejamento anual (D1, p. 87).

[...] estou iniciando a aplicação, mas meu temor é que trabalhado dessa forma vamos 
deixar de lado conteúdos primordiais para o ensino, haja vista que trabalharíamos com os interesses dos alunos, ou seja, eles que escolhem o que aprender" (D1, p. 86).

[...] utilizando um tema livre para a Modelagem Matemática, não cumprimos o currículo (T2, p. 293).

Ainda destaca-se que T2 amplia o olhar em relação às prescrições — como, por exemplo, o cumprimento do currículo - em atividades de modelagem. Recorrendo aos aportes da Clínica da Atividade e da Ergonomia, T2 apresenta que as prescrições condicionam e constituem 0 trabalho docente e, portanto, devem ser levadas em consideração no momento do planejamento da atividade de modelagem, para além de ser apontado como obstáculo ou dificuldade.

A tese $\mathrm{T} 1$ teve como participantes da pesquisa professores de séries iniciais e apresentou dificuldades referentes ao conhecimento do conteúdo que será objeto de ensino, no sentido atribuído por Schulman (1986). As passagens apresentadas a seguir sinalizam para o exposto:

É difícil trabalhar com a matemática porque eu não tenho formação em matemática [...]. Às vezes falta um domínio maior e isso é uma coisa que às vezes é complicado. Então eu quero aprender mais matemática para lidar com essas dificuldades (T1, p. 98).

[...] Para a realização da atividade, as professoras apresentaram algumas dificuldades para se referir e mobilizar conceitos matemáticos que lhes permitiriam maior fidedignidade aos dados obtidos para concluir a medição do terreno (T1, p. 126).

As dificuldades apresentadas talvez sejam decorrentes da própria formação acadêmica e constituem-se em balizadores para orientar outras ações de formação continuada nessa perspectiva, denotando um campo de pesquisa em desenvolvimento.

\section{Uma síntese possível}

Este mapeamento teve como finalidade reconhecer as pesquisas realizadas acerca da temática Modelagem Matemática e Formação Continuada, possibilitando uma visão geral sobre o que está sendo pesquisado no cenário brasileiro de 2010-2019, bem como compreender a partir delas o desenvolvimento profissional (DP) dos professores participantes.

A partir dos estudos mapeados e analisados é possível destacar que (7:11) dissertações produzidas no período de 2010 a 2019, disponíveis no IBICT, são advindas do Programa de PósGraduação em Ensino ou do Programa de Pós-Graduação em Educação da Universidade Estadual do Oeste do Estado do Paraná (Unioeste), sob orientação do professor Tiago Emanuel Klüber. Ademais, nessas dissertações utilizou-se a pesquisa fenomenológica com 0 uso do 
software Atlas ti para análise dos dados, assinalando uma tendência metodológica desses programas de pós-graduação.

Em relação ao modelo de formação continuada, identificou-se cursos de curta duração ou com periodicidade permanente, nos quais o professor pesquisador também era 0 professor formador e orientava a realização das atividades. Os cursos de curta duração, foram organizados para a constituição dos dados da pesquisa ou são cursos com periodicidade frequente e participantes diferentes. Entretanto, compreendemos que mesmo os cursos com curta duração, mostraram contribuir para o DP dos professores participantes, haja vista o modo e os fundamentos da organização das formações.

Quanto à transição das atividades de MM na Educação Matemática para a sala de aula, embora tenham sido realizadas nos encontros de formação e posteriormente (re)organizadas para serem implementadas em sala de aula, destacamos que isso não se deu em todas as pesquisas, sinalizando para a necessidade de continuidade de propostas de formação continuada fundamentadas nos pressupostos da MM na Educação Matemática.

Outro ponto a ser destacado refere-se ao trabalho com professores dos Anos Iniciais, já que a pesquisa realizada com esses professores sinalizou para a fragilidade do conhecimento do conteúdo, conforme Schulman (1986), e a MM na Educação Matemática pode ser uma estratégia para ajudá-los não apenas nesse sentido, mas também no que diz respeito a uma outra maneira de organização e condução das aulas, o que na perspectiva deste autor é denominado de conhecimento pedagógico do conteúdo, ou seja, trata-se de um processo por meio do qual 0 professor pensa pedagogicamente sobre o conteúdo que ensina, e ao assim fazê-lo (re)significa esse conteúdo.

Como resultados, apontamos que as pesquisas analisadas abordam a formação continuada com Modelagem na perspectiva do DP dos professores e os espaços/tempo constituídos para as formações favoreceram o DP, pois contribuíram para o estabelecimento de reflexões sobre a prática docente, a fim de transformá-la; priorizaram o trabalho de modo colaborativo, considerando o contexto de trabalho dos professores, ou seja, constituindo uma formação que se aproxime da escola e dos problemas que os professores enfrentam.

Além disso, marcamos a transição da formação continuada para a sala de aula como um movimento de DP situado no fazer docente, visto que a partir da implementação das práticas de Modelagem na sala de aula pôde-se refletir sobre o desenvolvimento das mesmas e as 
dificuldades acerca do trabalho com Modelagem as quais estão marcadas no tempo para planejamento e desenvolvimento na sala de aula; no cumprimento do currículo; na insegurança do professor e na escolha do tema para o início do processo de modelagem. Além disso, a implementação da prática e a produção de narrativas sobre o seu desenvolvimento situa um movimento de aprendizagem docente e, portanto, de DP.

Disso, decorre que os espaços/tempo de formação continuada apresentados nas pesquisas analisadas são, parafraseando Fiorentini e Crecci (2013), catalisadores de desenvolvimento profissional e favorecem a inserção dos fundamentos da MM na Educação Matemática ao contexto específico de trabalho do professor e, portanto, são necessárias ações de formação (continuada) nessa perspectiva, a fim de ampliar a inserção das ideias da MM na sala de aula.

\section{Referências}

ALMEIDA, Lourdes Werle de; SILVA, Karina Pessôa da; VERTUAN, Rodolfo Eduardo. Modelagem Matemática na Educação Básica. São Paulo: Contexto, 2012.

BARBOSA, Jonei Cerqueira. As relações dos professores com a Modelagem Matemática. In: ENCONTRO NACIONAL DE EDUCAÇÃO MATEMÁTICA, 8, 2004, Recife. Anais do VIII ENEM Educação Matemática: um compromisso social. Recife: SBEM, 2004, p. 1-11.

BARBOSA, Jonei Cerqueira. Mathematical modelling in classroom: a critical and discursive perspective. ZDM, Karlsruhe, v. 38, n. 3, p. 293-301, jun. 2006.

BARBOSA, Jonei Cerqueira. As discussões paralelas no ambiente de aprendizagem modelagem matemática. Acta Scientiae, Canoas, v.10, n.1, jan.jjun. 2008.

BASSANEZI, Rodney Carlos. Ensino-aprendizagem com Modelagem Matemática. 3. ed. São Paulo: Contexto, 2013.

BRASIL. Ministério da Educação. Secretaria de Educação Básica. Base Nacional Comum Curricular. Educação Infantil e Ensino Fundamental. Brasília: MEC/SEB, 2017.

BIEMBENGUT, Maria Salett. Modelagem no Ensino Fundamental. Blumenau: EdFURB, 2014.

BIEMBENGUT, Maria Salett. Modelagem na Educação Matemática e na Ciência. São Paulo: Livraria da Física, 2016.

BURAK, Dionísio. Modelagem matemática: ações e interações no processo de ensinoaprendizagem. 1992. 130f. Tese (Doutorado em Educação) - Faculdade de Educação. Universidade Estadual de Campinas. Campinas. 
DIAS, Michele Regiane. Uma experiência com Modelagem Matemática na formação continuada de professores. 2005. 121f. Dissertação (Mestrado em Ensino de Ciências e Educação Matemática) - Centro de Ciências Exatas. Universidade Estadual de Londrina. Londrina.

FERREIRA, Ana Cristina. Um olhar retrospectivo sobre a pesquisa brasileira em formação de professores de Matemática. In: FIORENTINI, Dario. (Org). Formação de professores de Matemática: explorando novos caminhos com outros olhares. Campinas: Mercado de Letras, 2003, p. $19-50$.

FIORENTINI, Dario. et al. Formação de professores que ensinam Matemática: um balanço de 25 anos da pesquisa brasileira. Educação em Revista, Belo Horizonte, n. 36, 137-160, dez. 2002.

FIORENTINI, Dario; CRECCI, Vanessa. Desenvolvimento profissional docente: um termo guardachuva ou um novo sentido à formação? Formação Docente, Mariana, v. 5, n. 8, p. 11-23, jan./jun. 2013.

GARCÍA, Carlos Marcelo. Formação de professores: para uma mudança educativa. Tradução de Isabel Narciso. Porto: Porto Editora, 1999.

GARCIA, Carlos Marcelo. PRYJMA, Marielda Ferreira. A aprendizagem docente e os programas de desenvolvimento profissional. In: PRYJMA, Marielda Ferreira. (Org.). Desafios e trajetórias para o desenvolvimento profissional docente. Curitiba: EdUTFPR, 2013, p. 37-54.

IMBERNÓN, Francisco. Formação continuada de professores. Tradução Juliana dos Santos Padilha. Porto Alegre: Artmed, 2010.

MINAYO, Maria Cecília de Souza (Org). Pesquisa Social: teoria, método e criatividade. 18 ed. Petrópolis: Vozes, 2001.

NÓVOA, Antônio. (Coord.). Os professores e a sua formação. 2. ed. Lisboa: Dom Quixote, 1995.

OLIVEIRA, Andreia Maria Pereira de. Modelagem Matemática e as tensões nos discursos dos professores. 2010. 199f. Tese (Doutorado em Ensino, Filosofia e História das Ciências). Universidade Federal da Bahia. Salvador.

PASSOS, Cármen Lúcia Brancaglion. et al. Desenvolvimento profissional do professor que ensina Matemática: uma meta-análise de estudos brasileiros. Quadrante, Lisboa, v. 15, n. 1 e 2, 2006.

PONTE, João Pedro. (Org.). Práticas profissionais dos professores de Matemática. Lisboa: Universidade de Lisboa, 2014.

SHULMAN, Lee. Those who understand: knowledge growth inteaching. Educational Researcher, v. 15, n. 2, p. $4-14,1986$.

STAKE, Robert E. Pesquisa qualitativa: estudando como as coisas funcionam. Tradução de Karla Reis. Porto Alegre: Penso. 2011. 